\title{
A CLINICO-PATHOLOGICAL STUDY OF CORONARY DISEASE
}

BY

\author{
P. J. D. SNOW, A. MORGAN JONES, AND K. S. DABER \\ From the Departments of Cardiology and Pathology, University of Manchester
}

In a previous paper (Snow et al., 1955) the pathological findings in the hearts of twenty-five patients with coronary disease were described. In the present paper these findings, together with those in an additional seven patients, are correlated with the clinical features.

Material. Thirty-two patients were studied, all with clinical evidence of ischæmic heart disease. Those in whom hypertension or valvular lesions may have contributed to the ischæmic symptoms were not excluded. Sixteen of the patients had been under the care of the Department of Cardiology and all had been observed personally by one of us; 11 had been under the care of other units of Manchester Royal Infirmary, and 5 had been admitted to Crumpsall Hospital, Manchester. Only cases with a full clinical history were included in the series, which was not consecutive.

Symptoms occurring within three months of death were the main basis of this study since up to this time the age of a myocardial infarct can be estimated pathologically and correlated chronologically with the clinical events.

At necropsy the coronary arteries were injected with a radiopaque medium and radiographed to locate all occlusions; the myocardium was then serially sectioned and all lesions examined histologically by the technique previously described (Snow et al., 1955).

\section{RESULTS}

Age and Sex Distribution. The series included 29 men and 3 women whose ages ranged from forty-one to seventy-eight, with a maximum incidence in the sixth decade. This accords with the age incidence of coronary disease found by other authors (Master et al., 1939; and Friedberg, 1950).

The Symptoms of Coronary Occlusion. Of the 53 occlusions only seven occurred without infarction and all these seven occlusions were in arteries supplying previously infarcted areas. In none of these seven were any clinical symptoms associated with the occlusions but, since it is not possible to assess the age of occlusions accurately, these findings should be regarded only as suggesting that occlusion without infarction may be asymptomatic.

The Symptoms of Myocardial Infarction. Seventy-seven infarcts were present of which 52 were recent (i.e. less than three months old) and could be accurately correlated with the symptoms. The other 25 infarcts were healed and of indefinite age so that chronological correlation was impossible.

Of the 52 recent infarcts, $28(54 \%)$ corresponded with episodes of prolonged cardiac ischæmic pain, two $(4 \%)$ with the onset of angina of effort and two $(4 \%)$ with the onset or aggravation of dyspnœa. Nineteen infarcts $(36 \%)$ gave rise to no apparent symptoms, and one occurring while the patient was comatose is excluded.

Although accurate chronological correlation with the symptoms was impossible in the case of the 25 healed infarcts, it was interesting to note that thirteen could have corresponded with the onset of angina of effort, three with the aggravation of existing angina, six with prolonged cardiac pain, and one with the onset of dyspnœa. In two no symptoms were recorded.

Asymptomatic and Atypical Infarcts. Twenty-three $(45 \%)$ of the 51 recent infarcts whose symptoms were known were unassociated with prolonged pain. These infarcts were distributed between fifteen hearts in eleven of which other infarcts that were associated with typical prolonged 
pain were also present. An analysis of these lesions was made in an attempt to discover reasons for the lack of typical symptoms.

No correlation could be found between the symptoms and the size or site of infarcts, or whether painless infarction preceded or followed clinically recognizable infarction when this co-existed in the same heart. When the infarcts were grouped according to their precipitating causes (i.e. with or without occlusion), however, a difference was apparent (see Table I).

TABLE I

Clinical Signs of Recent Cardiac Infarcts

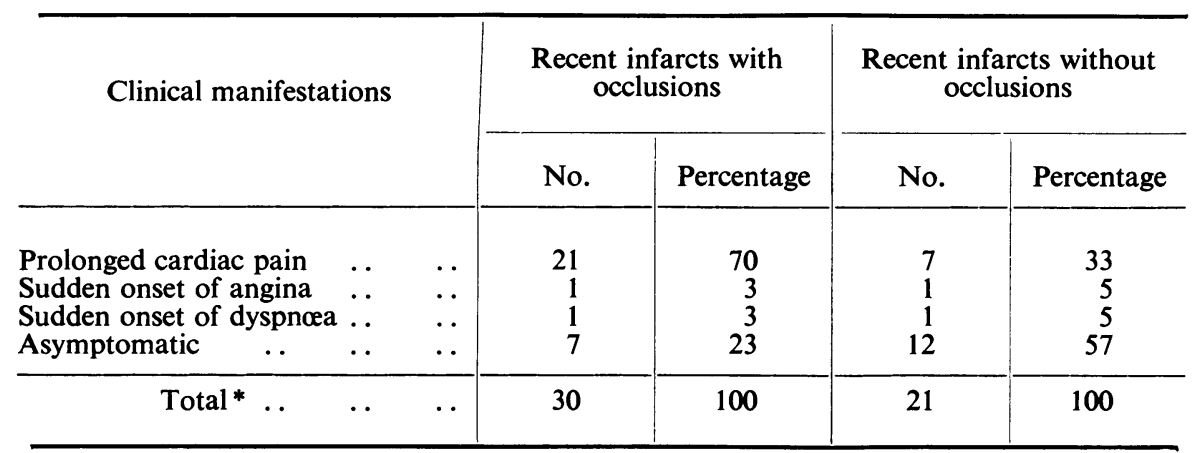

* Excludes an infarct that occurred in a comatose patient.

Thirty of the 51 recent infarcts were due to occlusion and $21(70 \%)$ of these caused prolonged pain. On the other hand, 21 were either completely unrelated to occlusion or else arose by extension from previous infarcts without further occlusion (Snow et al., 1955) and of these, only seven (33\%) caused prolonged pain. Although these numbers are small, this difference is unlikely to have arisen by chance $\left(\chi^{2}=5 \cdot 33: \rho \bumpeq 0 \cdot 02\right)$.

The Pathological Significance of Prolonged Cardiac Pain. Thirty-one episodes of chest pain or discomfort judged to be of cardiac origin and of over half an hour's duration occurred within three months of death. Up to this time the age of an infarct may be assessed with a reasonable degree of accuracy, hence permitting correlation with the symptoms. In twenty-eight of these episodes, infarcts of corresponding ages were found at necropsy.

In two instances of prolonged pain without corresponding evidence of infarction possible explanations were obvious. In one case two episodes of pain occurred on the fifteenth and seventeenth days before death and at autopsy an infarct fourteen to eighteen days old was found: a difference of two days in the ages of two confluent infarcts would not be detectable when both were over two weeks old and it is possible that both episodes of pain were associated with infarction. In another the episode of pain occurred the day before death and, although no corresponding infarct was found post mortem, histological changes of infarction might have appeared had death been postponed.

The remaining episode of pain occurred two months before death but no corresponding infarct could be found post mortem. This is the only clear exception to the general conclusion that cardiac pain lasting more than half an hour is an indication of myocardial infarction.

The Pathological Significance of the Onset or Aggravation of Angina of Effort. There were 24 episodes of the sudden onset or aggravation of angina of effort. Unfortunately for purposes of accurate correlation, only four of these occurred within three months of death. In three of these four cases angina was the only symptom of coronary disease. In two the onset of angina coincided with the histologically determined ages of the infarcts. In the third angina began three weeks before death but no corresponding infarct was found. In the one case in which angina beginning three months before death was followed by an attack of prolonged pain on the day before death, there was a small healed infarct that could have been three months old. 
Of the 20 instances in which angina began more than six months before death, two had no infarcts that could have corresponded with them, but in all the rest healed infarcts were present, and since prolonged cardiac pain was absent in all but two cases until two months before death, the onset or aggravation of angina of effort was the only recorded clinical manifestation of these infarcts.

\section{Discussion}

Despite numerous clinico-pathological studies there is still disagreement about the clinical manifestations of coronary occlusion and myocardial infarction, and the pathological significance of angina of effort and prolonged cardiac pain at rest. This uncertainty is reflected in the present confused terminology, and as Levy (1948) stated " accurate terminology is not mere quibbling, for it promotes clear thinking and intelligent therapeutic procedure." Freedberg et al. (1948) pointed out that the recognition of the various types of cardiac pain has been accompanied by a diversity of opinion concerning the applicable diagnostic terms. There is still, for example, disagreement as to the correct designation for an attack of prolonged cardiac ischæmic pain and the terms coronary thrombosis, coronary occlusion, and myocardial infarction have all been used, often apparently indiscriminately (Editorial, Brit. med. J., 1, 1499, 1951).

The Symptoms and Diagnosis of Coronary Occlusion. At one time coronary occlusion was believed to be the cause of the clinical syndrome of " coronary thrombosis," but many now believe that the symptoms are due to myocardial infarction rather than coronary occlusion.

Friedberg (1950) stated, without quoting pathological evidence, that the acute onset of angina of effort may be due to an occlusion without an ensuing infarct, whereas Blumgart et al. (1940) concluded that occlusions alone do not cause any symptoms and it is the resultant infarct, if any, that is responsible for the clinical manifestations. Master and his colleagues (Master et al., 1941 and 1944; Master, 1944 and 1946) on the other hand have repeatedly maintained that it is possible to distinguish infarcts due to occlusions from those due to extra-coronary factors by clinical and electrocardiographic criteria. There is thus a diversity of opinion as to the clinical manifestations and diagnostic criteria of coronary occlusions.

Two points must be made from the present observations. First, unlike infarcts occlusions cannot be accurately " aged," though they can be classified as recent, healing, or old, and attempts to correlate symptoms with them chronologically might be fallacious. Secondly, in this study occlusions without infarction were uncommon and when present were apparently asymptomatic, but this conclusion is subject to the reservation about assessing the age of the occlusion.

None the less, infarction without occlusion may have somewhat different clinical manifestations from infarction due to occlusion, since only 7 of 21 infarcts without occlusions or due to extensions of previous infarction without new occlusion caused typical prolonged cardiac pain, compared with 21 of 30 infarcts due to occlusions. These proportions are almost identical with those of Gorham and Martin (1938), and Master and his colleagues also observed that pain was usually severe when infarction resulted from occlusion and was mild or absent when infarction was due to "coronary insufficiency."

These authors considered that the syndrome of severe prolonged cardiac pain with shock and a cardiogram showing abnormal Q waves, elevated RS-T segments and inverted T waves was diagnostic of infarction due to occlusion in 95 per cent of cases, but they were comparing the clinical and cardiographic manifestations of infarcts that they believed to be due to occlusion with infarcts due to gross general coronary insufficiency, which are usually subendocardial and associated with fairly characteristic cardiographic signs, thus constituting a distinct type of infarct. They have not taken into account the fact that the commoner transmural infarcts may also occur without occlusions. In the present series, the electrocardiographic changes were similar whether infarction was due to occlusion or not.

The suggestion of Blumgart et al. (1940) that the presence of an occlusion may be surmised when infarction occurs while the work of the heart is not increased, was not borne out by the present study in which infarcts occurred without occlusions in hearts of normal size while the patients were at rest 
and in the absence of valvular lesions or hypertension. This seems to us to be a point of considerable interest, but we cannot put forward any satisfactory explanation. For reasons that we hope to discuss in a subsequent paper, we believe that it is not simply due to missing the presence of coronary occlusions.

It is concluded that when solitary occlusions occur they appear to be asymptomatic, and there appear to be no criteria by which they may be recognized clinically. We do not think that it is justifiable to diagnose coronary occlusion clinically and, with Freedberg et al. (1948), we would like to see this clinical diagnosis discarded.

The Symptoms of Myocardial Infarction. Our observations conform to the general impression that the clinical manifestations of myocardial infarction may vary from prolonged cardiac pain at rest to brief pain on effort only, while in other cases pain may be replaced by dyspnœa or even by no apparent symptoms. Our figures emphasize the comparatively high proportion of cases $(46 \%)$ in which infarction fails to cause typical prolonged pain.

The problem of painless infarction is an important one and raises several questions. How often does it occur? Why is pain absent? Is the prognosis poor? The large and rather confused literature on this subject has been concerned almost exclusively with the first two questions and agreement has not been reached on either.

The Frequency of Painless Infarction. The published figures for the frequency of painless infarction vary widely because there has been little agreement on the interpretation of the term painless, and some authors refer to the number of episodes of coronary thrombosis which may not have meant infarction, while others refer not to the number of painless infarcts but to the cases in which they occurred, without allowing for the fact that both painful and painless infarcts may occur in the same heart. Further, the criteria for recognizing infarction have usually been purely clinical without pathological confirmation. In these circumstances it is not surprising that the reported incidence of painless infarction should vary from 1 to 61 per cent (Table II).

TABLE II

Percentage of Painless Infarcts

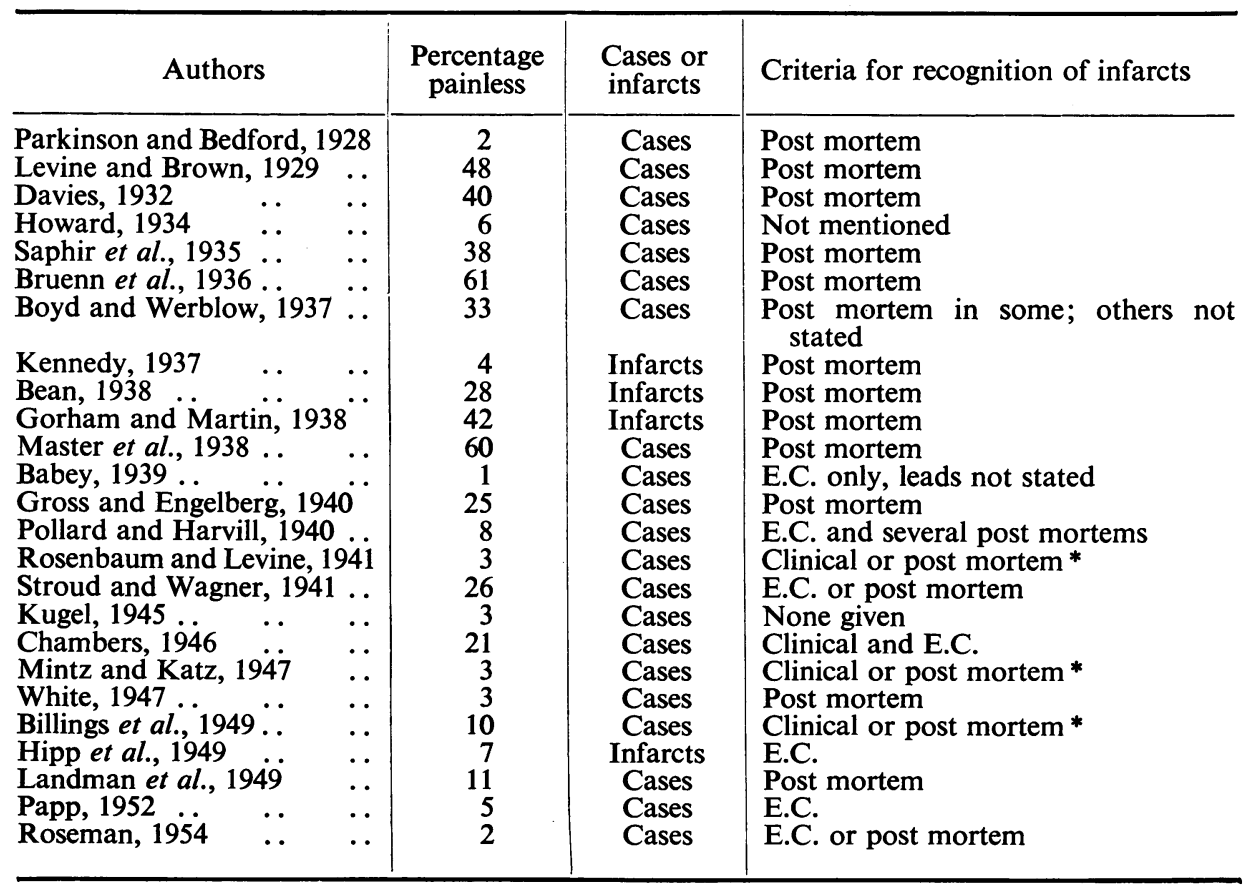

* Numberinot specified. 
In the present series 36 per cent of infarcts were completely without symptoms while 45 per cent were without typical prolonged pain and, since only cases with adequate clinical records and detailed pathological data were used, these results are probably comparatively accurate in this group of cases.

The designation asymptomatic, while correct as far as could be established, was used subject to certain reservations, for it obviously is not possible to question the patient soon after an apparently asymptomatic infarct has occurred and the possibility that vague, mild symptoms were present cannot be denied, but the distinction between an asymptomatic infarct and one with mild atypical symptoms is of no practical importance since neither would be diagnosed except by chance electrocardiography. A much more serious difficulty is the frequency with which patients appear to develop some degree of amnesia for the initial symptoms in severe infarction; although they may complain of severe pain when seen during the attack this is often denied when they are questioned a week later.

Speculations on the Explanation of Painless Infarction. Several explanations for the occurrence of painless infarction have been put forward but without much evidence. These speculations are summarized below, together with the main evidence against them.

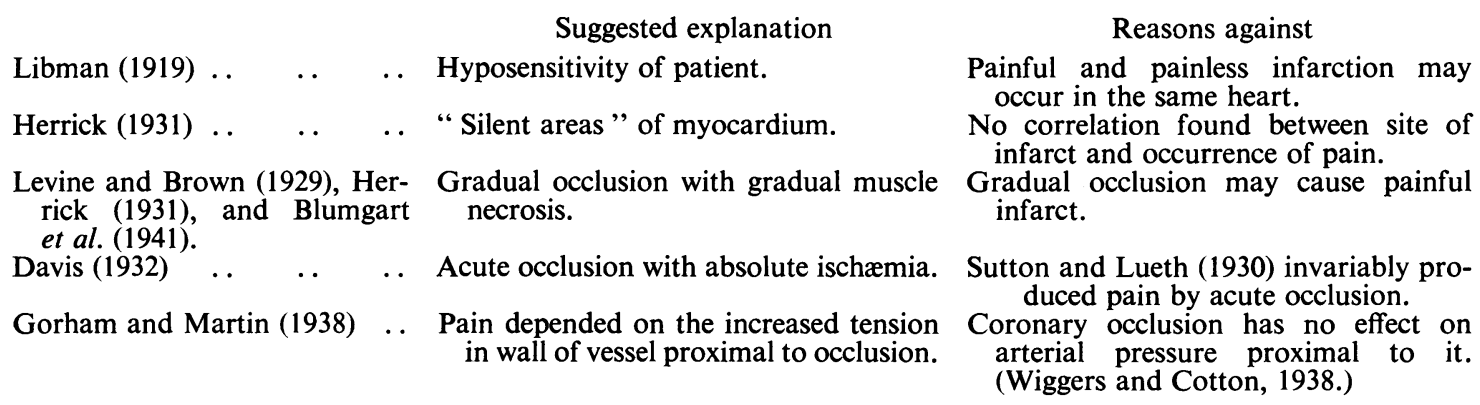

The occurrence of painless infarction is unquestioned and, whatever its incidence, its existence is a challenge to try to discover the reason or reasons for the absence of pain in some cases. Most attempts to do this have been made by trying to correlate known clinical factors (cardiac enlargement, hypertension, arrhythmia, etc. (Evans and Sutton, 1956)) or pathological observations (site, extent, collateral circulation, previous infarction, etc.) with the presence or absence of pain. Work on these lines has not led to any convincing conclusion and it may be that the problem must be approached from a broader point of view. The difficulty in understanding painless infarction is due to the widely held assumption that a degree of ischæmia sufficient to cause infarction must also cause pain, and it has then to be explained why some infarcts do not conform to this general rule.

Various attempts have been made to explain painless infarction without discarding this assumption, but we do not consider them satisfactory. In our view, insufficient attention has been paid to the importance of duration of ischæmia as opposed to its intensity. Experimentally, complete occlusion of a major coronary artery will not cause infarction provided that occlusion is relieved within twenty to thirty minutes (Tennant and Wiggers, 1935; Blumgart et al., 1941). In pain, on the other hand, the intensity of the ischæmia alone determines whether pain occurs, for even momentary occlusion is sufficient to cause pain (Sutton and Lueth, 1930) but if pain continues for over half an hour it is, from our own observations, almost invariably accompanied by infarction. Contrary therefore to the usual assumption, it is conceivable that a grade of ischæmia insufficient to produce pain may, if it persists for long enough, lead to infarction.

The Possible Dangers of Painless Infarction. Since patients are unlikely to rest after an asymptomatic infarct, the risks of extension or rupture of the infarct and ventricular fibrillation may be increased, and Bourne (1939), Le Roy and Snider (1941), Rosenbaum and Levine (1941), Boas (1942), Dressler (1944), Mintz and Katz (1947) and Billings et al. (1949), all concluded that infarcts with atypical symptoms have a higher mortality. In our clinical cases, infarcts that were not precipitated by occlusions were often painless and it is interesting that infarcts without occlusions 
accounted for a high proportion of cases of sudden death that have been studied. (These are not included in this series and will be reported elsewhere.)

The Diagnostic Significance of Prolonged Cardiac Pain and the Onset of Angina of Effort. There has been surprisingly little attempt to establish the pathological significance of the onset of angina despite its long clinical recognition, although there is now a general opinion that it may often signify coronary occlusion without infarction (Friedberg, 1950). In our series isolated occlusions seldom occurred and when they did so were asymptomatic so this view may need revision.

There is, however, some evidence to suggest that the onset of angina may indicate infarction with or without coronary occlusion. Both Obrastzow and Straschesko (1910) and Herrick (1912) reported cases in which myocardial infarcts proved at autopsy were associated with the onset of angina, and more recently Bourne (1939), Le Roy and Snider (1941), Boas (1942), Dressler (1944) and Wade and Morgan Jones (1951) all pointed out that the onset of angina may signify infarction, and mentioned the danger attached to this presentation owing to the risk of sudden death from failure to recognize and treat the infarct. Riseman and Brown (1937) found that the blood sedimentation rate was increased in 50 per cent of cases with angina of recent onset, and believed this to be due to myocardial damage.

Our observations confirm that the acute onset of angina may be the clinical counterpart of infarction but do not indicate how often this is so, or how such cases can be distinguished from those without infarction. From the practical point of view, however, it seems advisable to regard the recent acute onset of angina as an indication that infarction has occurred.

The uncertain significance of an attack of prolonged cardiac pain is reflected in the present confused terminology for the terms coronary thrombosis, coronary occlusion, and myocardial infarction have all been used apparently synonymously. Possibly because of the uncertain significance of such pain there has been a tendency to belittle its importance when it occurs without electrocardiographic evidence of infarction. There is now, however, an increasing body of opinion that regards prolonged cardiac pain as usually significant of infarction (Blumgart et al., 1940; Master et al., 1944; Freedberg et al., 1948; Friedberg, 1950; and Wood, 1950). Strong confirmation of this view was afforded by the present study in which there were 31 episodes of cardiac pain lasting for over half an hour and at least 28 of these were found to have corresponding infarcts post mortem. Cardiac pain of this duration is therefore quite a reliable indication that infarction has occurred.

\section{SUMMARY}

The symptoms of 32 patients with coronary disease have been correlated with the post-mortem findings. No evidence was found of coronary occlusion causing symptoms, which were always attributable to myocardial infarction.

In particular, prolonged cardiac pain of over half an hour duration was found to be a very reliable indication of myocardial infarction.

A high proportion of infarcts, however, did not give rise to any recognizable symptoms and the possible reasons for this are discussed.

We are grateful to the physicians of the Royal Infirmary and Crumpsall Hospital, Manchester, for permission to study their cases.

\section{REFERENCES}

Babey, A. M. (1939). New Engl. J. Med., 220, 410.

Bean, W. B. (1938). Ann. intern. Med., 12, 71.

Billings, F. T., Kalstone, B. M., Spencer, J. L., Ball, C. O. T., and Meneely, G. R. (1949). Amer. J. Med., 7, 356.

Blumgart, H. L., Gilligan, D. R., and Schlesinger, M. J. (1941). Amer. Heart J., $22,374$.

, Schlesinger, M. J., and Davis, D. (1940). Amer. Heart J., 19, 1.

Boas, E. P. (1942). Amer. Heart J., $23,1$.

Bourne, G. (1939). Lancet, 1, 1155.

Boyd, L. J., and Werblow, S. C. (1937). Amer. J. med. Sci., 194, 814.

Bruenn, H. G., Turner, K. B., and Levy, R. L. (1936). Amer. Heart J., 11, 34.

Chambers, W. N. (1946). New Engl. J. Med., 235, 347. 
Davis, N. S. (1932). J. Amer. med. Ass., 98, 1806.

Dressler, W. (1944). Amer. Heart J., 28, 81.

Evans, W., and Sutton, G. C. (1956). Brit. Heart J., 18, 259.

Freedberg, A. S., Blumgart, H. L., Zoll, P. M., and Schlesinger, M. J. (1948). J. Amer. med. Ass., $138,107$.

Friedberg, C. K. (1950). Diseases of the Heart. Philadelphia and London.

Gorham, L. W., and Martin, S. J. (1938). Arch. intern. Med., 62, 821.

Gross, H., and Engelberg, H. (1940). Amer. J. Med., 199, 621.

Herrick, J. B. (1912). J. Amer. med. Ass., 59, 2015. (1931). Amer. Heart J., 6, 587.

Hipp, H. R., Behrman, J. M., and Heyer, H. E. (1949). American Practitioner, 4, 64.

Howard, T. (1934). Medical Times and Long Island med. J., 62, 337.

Kennedy, J. A. (1937). Amer. Heart J., 14, 703.

Kugel, M. A. (1945). J. Mt. Sinai Hosp., 12, 422.

Landman, M. E., Anhalt, H. S., and Angrist, A. (1949). Arch. intern. Med., 83, 665.

Le Roy, G. V., and Snider, S. S. (1941). J. Amer. med. Ass., 117, 2019.

Levine, S. A., and Brown, C. L. (1929). Medicine, 8, 245.

Levy, R. L. (1948). J. Amer. med. Ass., 138, 114.

Libman, E. (1919). Trans. Ass. Amer. Phys., 34, 138.

Master, A. M. (1944). Ann. intern. Med., 20, 161. (1946). N.Y.Med., $2,19$.

—, Dack, S., and Jaffe, H. L. (1938). J. Amer. med. Ass., 110, 1415.

- _ _- _- _ (1939). Arch. intern. Med., 64, 767.

- - Gubner, R., Dack, S., and Jaffe, H. L. (1941). Arch. intern. Med., 67, 647.

, Jaffe, H. L., Dack, S., and Grishman, A. (1944). Amer. Heart J., 27, 803.

Mintz, S. S., and Katz, L. N. (1947). Arch. intern. Med., 80, 205.

Obrastzow, J. P., and Straschesko, N. D. (1910). Z. klin. Med., 71, 116.

Papp, C. (1952). Brit. Heart J., 14, 250.

Parkinson, J., and Bedford, D. E. (1928). Lancet, $1,4$.

Pollard, H. M., and Harvill, T. H. (1940). Amer. J. med. Sci., 199, 628.

Riseman, J. E., and Brown, M. G. (1937). Amer. J. med. Sci., 194, 392.

Roseman, M. D. (1954). Ann. intern. Med., 41, 1.

Rosenbaum, F. F., and Levine, S. A. (1941). Arch. intern. Med., 68, 913.

Saphir, O., Priest, W. S., Hamburger, W. W., and Katz, L. N. (1935). Amer. Heart J., $10,567$.

Snow, P. J. D., Morgan Jones, A., and Daber, K. S. (1955). Brit. Heart J., 17, 503.

Stroud, W. D., and Wagner, J. A. (1941). Ann. intern. Med., 15, 25.

Sutton, D. C., and Lueth, H. C. (1930). Arch. intern. Med., 45, 827.

Tennant, R., and Wiggers, C. J. (1935). Amer. J. Physiol., 112, 351.

Wade, E. G., and Jones, A. Morgan (1951). Brit. Heart J., 13, 319.

White, P. D. (1947). Heart Disease. 3rd ed. New York.

Wiggers, C. J., and Cotton, F. S. (1933). Amer. J. Physiol., 106, 9.

Wood, P. (1950). Diseases of the Heart and Circulation. London. 